\title{
Role of early growth response 1 in liver metabolism and liver cancer
}

\author{
Nancy Magee, Yuxia Zhang \\ Department of Pharmacology, Toxicology \& Therapeutics, University of Kansas Medical Center, Kansas City, KS 66160, USA.
}

Correspondence to: Dr. Yuxia Zhang, Department of Pharmacology, Toxicology \& Therapeutics, University of Kansas Medical Center, 4089 HLSIC, MS 1018, 3901 Rainbow Blvd, Kansas City, KS 66160, USA. E-mail: lzhang5@kumc.edu

How to cite this article: Magee N, Zhang Y. Role of early growth response 1 in liver metabolism and liver cancer. Hepatoma Res 2017;3:268-77.

\section{Article history: \\ Received: 15 Aug 2017 \\ First decision: 25 Sep 2017 \\ Revised: 10 Oct 2017 \\ Accepted: 7 Nov 2017 \\ Published: 20 Nov 2017}

\section{Key words:}

Early growth response 1,

liver,

fibrosis,

injury,

liver cancer

\begin{abstract}
The liver is an essential organ for nutrient and drug metabolism - possessing the remarkable ability to sense environmental and metabolic stimuli and provide an optimally adaptive response. Early growth response 1 (Egr1), an immediate early transcriptional factor which acts as a coordinator of the complex response to stress, is induced during liver injury and controls the expression of a wide range of genes involved in metabolism, cell proliferation, and inflammation. In support of an important role of Egrl in liver injury and repair, deficiency of Egrl delays liver regeneration process. The known upstream regulators of Egrl include, but are not limited to, growth factors (e.g. transforming growth factor $\beta 1$, platelet-derived growth factor, epidermal growth factor, hepatocyte growth factor), nuclear receptors (e.g. hepatocyte nuclear factor $4 \alpha$, small heterodimer partner, peroxisome proliferator-activated receptor- $\gamma$ ), and other transcription factors (e.g. Sp1, E2F transcription factor 1). Research efforts using various animal models such as fatty liver, liver injury, and liver fibrosis contribute greatly to the elucidation of Egrl function in the liver. Hepatocellular carcinoma (HCC) represents the second leading cause of cancer mortality worldwide due to the heterogeneity and the late stage at which cancer is generally diagnosed. Recent studies highlight the involvement of Egrl in HCC development. The purpose of this review is to summarize current studies pertaining to the role of Egrl in liver metabolism and liver diseases including liver cancer.
\end{abstract}

\section{INTRODUCTION}

Early growth response 1 (Egr1) is an immediate early, zinc finger transcription factor that was first identified based upon its induction by nerve growth factor (NGF) in rat PC12 cells, which is why it was initially known as nerve growth factor inducible protein A (NGFI-A) $)^{[1]}$. Egr1 is one of four family members that also include Egr2, $\mathrm{Egr3}$, and $\mathrm{Egr}^{[2]}$. Also known as Krox24, zif268, and TIS8, Egr1 encodes a protein of 80-82 kDa that consists of three zinc finger DNA-binding motifs [Figure 1]. Thus, it is not elusive that zinc metal is crucial to the function of Egr1, such as nuclear localization ${ }^{[3]}$. Specifically, two of three zinc fingers interact with the nuclear localization sequence to promote Egr1 nuclear localization ${ }^{[3]}$. Depletion of the zinc metal reduces Egr1 promoter activity ${ }^{[4]}$. Transcriptional corepressors NGFI-A binding protein 1 and 2 (NAB1 and NAB2, respectively) repress Egr1, Egr2, and Egr3 transcriptional activity by binding to the respective repressor domains upstream of the zinc finger motifs and could potentially co-regulate Egr1 target genes ${ }^{[5-7]}$.

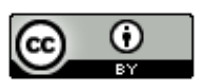

This is an open access article licensed under the terms of Creative Commons Attribution 4.0 International License (https://creativecommons.org/licenses/by/4.0/), which permits unrestricted use, distribution, and reproduction in any medium, as long as the original author is credited and the new creations are licensed under the identical terms.

For reprints contact: service@oaepublish.com

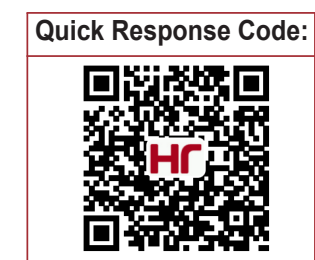




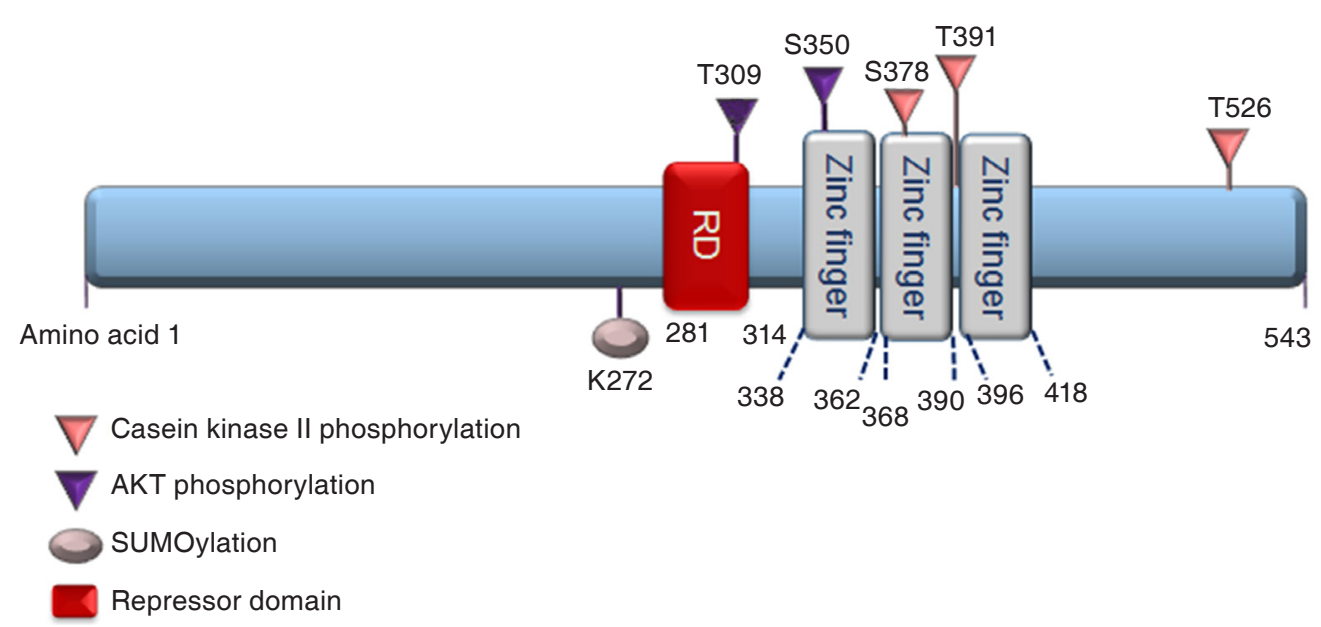

Figure 1: Schematic representation of EGR1 protein structure and post-translational modifications. EGR1 is a $543-a m i n o$ acid (aa) protein consisting of three Cysteine 2-Histidine $2\left(\mathrm{C}_{2} \mathrm{H}_{2}\right)$ zinc fingers DNA-binding domains, approximately 23 aa each. Zinc fingers 2 and 3 (amino acids 361-419) interact with amino acids 315-330 for EGR1 nuclear localization. The T309 and S350 sites are phosphorylated by protein kinase B (PKB, also known as AKT); whereas, S378, T391, and T526 sites are phosphorylated by casein kinase II. EGR1 protein can be SUMOylated by SUMO1 at K272. Transcriptional co-repressors NGFI-A binding protein 1 and 2 (NAB1 and NAB2, respectively) inhibit Egr1 transcriptional activity by binding to the repressor domain (RD). EGR1: early growth response 1

Egr1 expression can be induced by growth factors, ionizing radiation ${ }^{[8]}$, and insulin signaling ${ }^{[9]}$. Upstream regulators of Egr1 include transforming growth factor $\beta 1$ (TGF- $\beta 1)^{[10]}$, mitogen-activated kinase kinase-1, hepatocyte nuclear factor $4 \alpha$, and E2F transcription factor 1 (E2F1); whereas small heterodimer partner and peroxisome proliferator-activated receptor-y agonist are negative regulators of Egr1 ${ }^{[11-14]}$. Egr1 recognizes a highly conserved $\mathrm{G}-\mathrm{C}$-rich consensus nucleotide sequences (GCGGGGGCG) ${ }^{[15]}$ and either activates or represses the transcription of genes in a zinc-dependent manner. The presence of this specific Egr1 response element on its target gene promoter could thus be a good indication of direct transcriptional regulation by Egr1.

The expression of Egr1 has been described in liver, heart, brain, spleen, skeletal muscle, kidney, ovary and prostate ${ }^{[16]}$. Accordingly, important roles of Egr1 has been implicated in various cell types and pertain to embryogenesis ${ }^{[17]}$, cell growth and differentiation ${ }^{[18]}$, neurogenesis ${ }^{[19]}$, adipogenesis ${ }^{[20]}$, apoptosis ${ }^{[21]}$, fibrogenesis $^{[22]}$, and tumorigenesis ${ }^{[23]}$. Egr1 is one of the predominantly expressed EGR family members in the liver and liver-derived cell lines ${ }^{[24,25]}$. Extensive research has been conducted in animal models to elucidate Egr1 function in various liver diseases. In this review article, we begin by discussing the role of Egr1 in liver metabolism, and then focus on Egr1 in pathological states of liver with a particular interest in hepatocellular carcinoma (HCC). An unbiased discussion of what additional studies are necessary to aid in developing possible therapeutic interventions is also included.

\section{EGR1 AND LIVER METABOLISM}

Liver is a major site for synthesis, metabolism, storage and redistribution of glucose and lipids ${ }^{[26]}$. In the postprandial state, insulin is secreted from pancreatic beta cells in response to a high blood-sugar level. Circulating glucose is taken up by the hepatocyte via the glucose transporter type 2 - regulated by the serine/threonine kinase PI3K/AKT pathway in response to insulin signaling - and is phosphorylated to glucose-6-phosphate by liver glucokinase (Gck). Glucose-6-phosphate is either further processed for fuel via glycolysis, for nucleotide biosynthesis via pentose phosphate pathway or utilized for glycogen synthesis via glycogen synthase, depending on the systemic metabolic state. In addition, insulin further promotes de novo lipogenesis of fatty acids from acetyl-CoA or malonyl-CoA. In the fasting state, glucagon is secreted by the alpha cells of pancreas in response to a low blood-sugar level. Upon glucagon stimulation, the liver synthesizes glucose de novo as well as catabolizes glycogen to release glucose for other organs to use for energy. During this time, lipolysis in adipose tissues is increased and results in the production of free fatty acids, which is taken up by hepatocytes. Depending on the metabolic state, fatty acids are then either processed to triglycerides (TAGs) for storage or rapidly metabolized for the generation of ketone bodies that are, in part, oxidized by hepatic mitochondria. In the event of excess lipid accumulation in hepatocytes that exceeds $5 \%$ of liver weight, whether due to over nutrition or hyperglycemia, non-alcoholic fatty liver disease can develop. Thus, hepatic lipids can either derive from endogenous 
lipogenesis (de novo lipogenesis), which may account for up to $30 \%$ of TAGs in steatotic livers ${ }^{[27]}$, or derive from the active uptake of circulating fatty acids into the hepatocytes.

Glucose and insulin regulate Egr1 expression The contributions of glucose and insulin to Egr1 expression have been extensively studied in a variety of tissues and cell types. One earlier study showed that glucose rapidly and transiently induces Egr1 mRNA in SV40-transformed murine pancreatic beta-cell line MIN6 cells that is accompanied with an induction of insulin ${ }^{[28]}$. This study also demonstrated that the induction of Egr1 by glucose was unique to beta cells since glucose couldn't induce Egr1 expression in $\mathrm{NIH}$ 3T3 fibroblasts or hepatocytes ${ }^{[28]}$. The results raise a question whether glucose regulates Egr1 expression requires insulin signaling activation. Later, another study showed that in vascular endothelial cells, glucose and insulin independently regulated Egr1 expression and they had an additive effect to induce Egr1 in the co-treatment ${ }^{[29]}$. Specifically, glucose mediates its effects through activation of PKC while insulin acts through the extracellular signal-regulated kinase (ERK1/2) pathway ${ }^{[29]}$. Collectively, these studies suggest that glucose or insulin differentially regulates Egr1 expression in a cell-type dependent manner.

Insulin regulates Egr1 expression in hepatoma cells ${ }^{[0]}$ and in non-liver-derived cells overexpressed with insulin receptors ${ }^{[30,31]}$. Keeton et al. ${ }^{[9]}$ showed that in rat hepatoma H4IIE cells, insulin treatment rapidly and transiently induced Egr1 mRNA, reaching its maximum levels by $15 \mathrm{~min}$, which was coordinately regulated by a regulatory network involving MAPK kinase (MEK)ERK, p38 MAPK, and PI3-kinase (PI3K). In addition, the authors found that the activation of ERK1/2 was essential for the induction of Egr1 in response to insulin that could be further modulated by alterations in the activity of the p38 MAPK pathway ${ }^{[9]}$. By contrast, inhibition of the PI3K pathway augmented insulin's effect on Egr1 expression, suggesting that some factor downstream of PI3K may partially inhibit induction of Egr1. Of particular interests, Egr1 has been implicated to mediate the regulation of insulin on genes in liver metabolism, including hepatic malic enzyme $(\mathrm{ME})^{[32,33]}$ and apolipoprotein A-I gene $(\mathrm{ApoA} 1)^{[34]}$. Taken together, these studies suggest that induction of Egr1 in response to insulin is vital to insulin's action on liver metabolism.

\section{Egr1, insulin resistance, and obesity}

Insulin resistance is a central defect in type 2 diabetes mellitus (T2DM). The link between Egr1 and insulin resistance is originally from the observation that Egr1
mRNA is highly increased in adipocytes from diabetic mice $^{[35]}$. PI3K/Akt pathway is activated upon insulin stimulation, which is required for glucose uptake and glycogenesis to lower circulating glucose level ${ }^{[36]}$. Meanwhile, insulin stimulates the activation of MAPK (ERK1 and 2) that promotes insulin resistance ${ }^{[37]}$. Thus, the balance between PI3K/Akt and MAPK signaling pathway is critical to maintain insulin sensitivity. Egr1 transcriptionally regulates phosphatase and tensin homologue (PTEN), a suppressor of PI3K/Akt signaling $^{[38]}$. Meanwhile, Egr1 regulates geranylgeranyl pyrophosphate synthase (GGPPS), an activator of ERK/MAPK signaling ${ }^{[39]}$. Thus, inhibiting Egr1 in adipocyte simultaneously blocks MAPK signaling and augments PI3K/Akt signaling, and subsequently improves insulin sensitivity ${ }^{[40]}$. Collectively, these studies suggest that pharmacological targeting adipocyte Egr1 could be potentially applied for developing novel treatment for T2DM.

Obesity commonly coexists with Insulin resistance. The link of Egr1 to obesity and obesity-associated fatty liver has been reported in mouse studies. For example, whole body Egr1-deficient mice fed a high fat diet are less susceptible to diet-induced obesity and obesity-associated disorders such as insulin resistance, hyperinsulinemia, hyperlipidemia, and fatty liver, which largely depends on the increase of energy expenditure in the adipose tissue of Egr1-null mice ${ }^{[20]}$. These studies suggest that the upregulation of Egr1 in adipocytes is involved in promoting metabolic disorders and that targeting Egr1 in adipocyte could be useful for the obesity treatment.

The report of Egr1 function in liver steatosis is somehow contradictory. One earlier study showed that Egr1 expression levels in the liver are positively correlated to high caloric intake in mice, humans, and non-human primates ${ }^{[41]}$. In addition, wholebody $\mathrm{Egr1}^{-1-}$ mice are protected from chronic ethanolinduced fatty liver due to the decreased expression and release of TNFa from macrophages ${ }^{[42]}$. However, recent studies highlight that increasing Egr1 levels in the liver ameliorates diet-induced fatty liver disease. For example, the white pitaya (hylocereusundatus) juice attenuates diet-induced liver steatosis and improves insulin sensitivity in C57BL/6J mice, which is accompanied by an increase in hepatic Egr1 mRNA level ${ }^{[43]}$. Thus, future research focusing on hepatocytespecific Egr1 function in liver metabolism will be very valuable.

\section{Egr1 and cholesterol biosynthesis}

Cholesterol is an essential component for cell membrane and serves as the precursor to all steroid 
hormones. However, high intracellular cholesterol is toxic to cells and high blood levels of cholesterol increase the risk for atherosclerosis development ${ }^{[44]}$. Therefore, the overall cholesterol level is tightly controlled in the body. The liver plays a central role in this regulation by balancing multiple pathways involved in de novo cholesterol biosynthesis, cholesterol conversion to bile acids, biliary cholesterol excretion, and reverse cholesterol transport ${ }^{[45]}$. Sterol response element binding proteins (SREBPs) are important transcription factors that regulate expression of genes in lipid metabolism including fatty acids and cholesterol synthesis. Three isoforms (SREBP-1a, SREBP-1c, and SREBP-2) have been identified in mammals. SREBP-1 mainly regulates genes required for fatty acid biosynthesis and SREBP-2 is responsible for the induction of genes involved in cholesterol biosynthesis and uptake, including HMG-CoA synthase (Hmgcs) and low-density lipoprotein receptor $(L d l r)^{[46]}$.

Egr1 regulates the expression of cholesterol biosynthetic genes, such as Hmgcs, farnesyldiphosphate synthase ( $F d p s)$, farnesyl-diphosphate farnesyltransferase 1 (Fdft1), lanosterol synthase (Lss), sterol-4a-carboxylate 3-dehydrogenase ( $N s d h l)$, and malic enzyme (Me1), in rat hepatomaH4IIE cells ${ }^{[24]}$. Additionally, Egr1 acts in concert with SREBP-2 to mediate insulin-induced cholesterol biosynthesis in the liver $^{[24]}$. Oncostatin M (OM) is a gp130 family member produced by the F4/80-positive macrophages ${ }^{[47]}$. In human hepatoblastoma HepG2 cells, Egr1 is induced by $\mathrm{OM}$ and binds to the sterol-independent regulatory element (SIRE) in LDLR promoter region with coactivator CCAAT/enhancer binding protein-beta $(\mathrm{C} /$ EBP $\beta$ ) and activates LDLR transcription ${ }^{[48,49]}$. Together, these studies point to Egr1 as an important modulator of cholesterol metabolism in the liver.

\section{EGR1 AND LIVER REGENERATION}

The liver has a tremendous capacity to regenerate after injury, which is a highly coordinated process involving both liver parenchymal and non-parenchymal cells. During liver regeneration, adult hepatocytes enter the cell cycle ( $G 0$ to $\mathrm{G} 1$ ) and progress through the cell cycle (G1 to $M)$ until liver mass is restored ${ }^{[50]}$. Many signals regulate the process of liver regeneration ${ }^{[51]}$. For example, lipopolysaccharide and cytokines are important mediators of the initiation phase ${ }^{[52]}$. Growth factors such as hepatocyte growth factor (HGF) and epidermal growth factor (EGF) regulate the progression phase ${ }^{[53]}$. TGF- $\beta 1$ signals later terminate hepatocyte proliferation ${ }^{[54]}$. Additionally, growth arrest-specific 1 (Gas1), a cell proliferation inhibitor, is induced during liver regeneration at the cycle $\mathrm{G} 1 /$
$S$ transition, contributing to the final termination of regeneration ${ }^{[5]}$. Perturbations in the liver-regenerative response cause prolonged liver injury and delayed liver recovery.

The role of Egr1 in liver regeneration was first suggested by animal studies demonstrating that Egr1 was immediately induced during the initiation phase of liver regeneration ${ }^{[56,57]}$. Using a transgenic Egr1 luciferase (Egr1-luc) mouse model, Dussmann et al. ${ }^{[14]}$ demonstrated that Egr1 expression was increased at the site of wound healing in partial hepatectomy. Another earlier study showed that Egr1 expression significantly increased after $15 \mathrm{~min}$ and subsided within $60 \mathrm{~min}$ after partial hepatectomy in rat livers ${ }^{[56]}$. More recent studies in mice have extended the peak of Egr1 induction to $12 \mathrm{~h}$ in partial hepatectomy-induced liver regeneration ${ }^{[58]}$ and to $2 \mathrm{~h}$ in carbon tetrachloride $\left(\mathrm{CCl}_{4}\right)$ exposure-induced liver regeneration ${ }^{[18]}$. The specific signals that regulate Egr1 expression during liver regeneration are not quite understood, a number of candidates are worthy of consideration. For example, extracellular ATP has been implicated as a potent stimulus for Egr1 expression ${ }^{[59]}$. P2Y purinoceptor 2 (P2Y2) is a G protein coupled receptor that is activated by ATP in hepatocytes. The fact that the induction of Egr1 is impaired in $P 2 Y^{-/-}$liver subjected to partial hepatectomy indicates that P2Y2 may regulate Egr1 expression during liver regeneration ${ }^{[60]}$. Additional candidates that regulate Egr1 expression are likely to include interleukin-6 (IL-6) and C/EBP $\beta$, because the induction of Egr1 has been shown to be impaired in $I L-6^{-/-}$or $C / E B P \beta^{-/-}$liver subjected to partial hepatectomy ${ }^{[61,62]}$.

EGR1 is essential for cell-cycle entry and progression during liver regeneration as Egr1 directly regulates cell cycle mediators. Lai et al. ${ }^{[63]}$ found that Egr1-deficient mouse livers had a substantially lower recovery rate after liver injury, which was accompanied with the reduced expression of cell cycle mediators such as Cyclin D1, Cyclin E, and proliferating cell nuclear antigen. After subcutaneous administration of $\mathrm{CCl}_{4}$, Egr1-deficient mice exhibited increased liver injury and delayed cell cycle progression ${ }^{[18,58]}$. Acute ethanol dosing of $\mathrm{Egr}^{-1-}$ mice also resulted in exacerbated liver injury associated with impaired liver repair ${ }^{[64]}$. Collectively, these studies suggest that Egr1 and its regulated cell-cycle entry and progression is critical for liver regeneration. Additionally, Egr1 contributes to the regulation of a large number of genes required for the regenerative response, including cell division cycle 20 (cdc20), a key regulator of the mitotic anaphasepromoting complex, and cytokines necrosis factoralpha (TNFa), IL-6, and lymphotoxin-beta ${ }^{[14,18,57,65,66]}$. 
Therefore, Egr1 plays a critical role in liver regeneration after injury.

\section{EGR1 IN LIVER FIBROSIS AND ACETAMINOPHEN-INDUCED HEPATOTOXICITY}

Liver fibrosis is the wound-healing response of the liver to chronic injury that entails cell proliferation, inflammation, angiogenesis, as well as synthesis and remodeling of extracellular matrix ${ }^{[67-70]}$. Prolonged tissue injury can lead to excessive accumulation of extracellular matrix in the organ, a hallmark of fibrosis. Egr1 has been shown to induce transcription of growth factors and stimulate collagen production in human fibroblasts and fibrosarcoma cells, suggesting the contribution of Egr1 to fibrogenesis ${ }^{[22,71]}$. TGF- $\beta 1$, a key regulator of fibrogenesis, is an upstream regulator of $\mathrm{Egr}^{\left[{ }^{[10]}\right.}{ }^{\text {; }}$ however, Egr1 also regulates the expression of TGF- $\beta 1$ in response to the hepatitis $B$ virus ${ }^{[72]}$, which hints to the existence of a possible feedback regulation between TGF- $\beta 1$ and Egr1 during fibrogenesis.

Acetaminophen (APAP) is widely used to treat pain and reduce fever. APAP is mainly metabolized by the liver, undergoing glucuronidation, sulfation, or $\mathrm{N}$-hydroxylation. The sulfate product is the primary, non-toxic metabolite in children; whereas, the glucuronide metabolite is the primary, non-toxic metabolite in adults. The hydroxylated product is the bioactivation of APAP by cytochrome 2E1 (Cyp2E1) that leads to the toxic, reactive metabolite, $\mathrm{N}$-acetylp-benzoquinone imine (NAPQI). The final attempt to prevent toxicity is to conjugate NAPQI to glutathione ${ }^{[73]}$. In the event of APAP overdose, the glutathione stores are depleted; the reactive metabolite binds to hepatic proteins, leading to hepatic necrosis. In western countries, acute liver injury due to APAP overdose is the main cause for drug-induced acute liver failure ${ }^{[74]}$. In addition, long-term application of APAP has been linked to the increased hepatic inflammation and liver fibrosis in patients ${ }^{[75]}$.

The report of Egr1 function in acute or chronic APAPinduced hepatotoxicity is contradictory. In an acute APAP-induced liver injury mouse model, both Egr1 mRNA level and transcriptional activity in hepatocytes are increased ${ }^{[76]}$. Inhibition on ERK1/2-mediated Egr1 transcriptional activation by caffeic acid (an organic compound found in coffee, fruit, and herbs) attenuates APAP-induced hepatotoxicity ${ }^{[76]}$, suggesting that inhibiting Egr1 activation is beneficial to protect against APAP-overdose induced acute hepatotoxicity. By contrast, a recent study using WT and $E g r 1^{-1-}$ mice in chronic APAP-induced liver injury has demonstrated that $\mathrm{Egr}^{-1-}$ livers exhibited a more severe hepatotoxicity and fibrotic response compared to WT mice under APAP overdose ${ }^{[77]}$. Collectively, these data support Egr1 as an important mediator in APAP-induced hepatotoxicity and liver fibrosis; however, whether Egr1 could act as an inducer or protector against APAPinduced liver injury has remained elusive. Additional studies using cell-type specific Egr1-deficient animals to determine the involvement of Egr1 in acute and chronic APAP-induced liver injury would be highly beneficial for a more clear definition of cell-type specific role of Egr1 in liver injury and fibrosis.

\section{EGR1 AND LIVER CANCER}

Egr1 is demonstrated to act as both a tumor suppressor and a tumor promoter in cancers. The tumorigenic role of Egr1 was described in prostate, skin and kidney cancers $^{[78]}$. By contrast, tumor suppressor activity of Egr1 was reported in fibrosarcoma, glioblastoma, lung and breast cancers ${ }^{[79,80]}$. The role of Egr1 in liver cancers remains elusive, as studies evaluating the role of Egr1 in liver cancer development and progression have reported contradicting conclusions.

Accumulating studies suggest Egr1 as a tumor suppressor in HCC. Egr1 is commonly downregulated in HCC tissues from humans and murine, indicating that the downregulation of Egr1 is related to HCC development ${ }^{[81]}$. However, mechanisms responsible for the downregulation of Egr1 in liver cancer remain unknown. A recent study has described that EGR1 carries mutational intratumoral heterogeneity and frameshift mutations in colorectal and gastric cancers which have high microsatellite instability ${ }^{[82]}$. Thus, it could be interesting to know whether the same mechanism could exist in liver cancer and contribute to the decrease of EGR1. Aberrant MAPK signaling activation is a key player in driving tumor proliferation ${ }^{[83-85]}$. Inhibition of P42/44MAPK in HepG2 cells leads to suppression on cell growth, proliferation, and survival, accompanied by an induction of Egr1 in tumor cells ${ }^{[86]}$. Recently, (125)I-UdR radionuclide therapy combined with Egr1-promoterbased interferon gamma (IFNY) gene therapy was described to efficiently reduce tumor proliferation and promote animal survivals in mice bearing $\mathrm{H} 22$ hepatomas ${ }^{[87]}$. Overexpression of Egr1 decreases the growth rate and tumorigenicity of the HCC cell line $\mathrm{HHCC}$ cells $^{[88]}$. Furthermore, Egr1 induces apoptosis in human hepatoma cells (HepG2 and Hep3B) that can be enhanced by synthetic chenodeoxycholic acid 


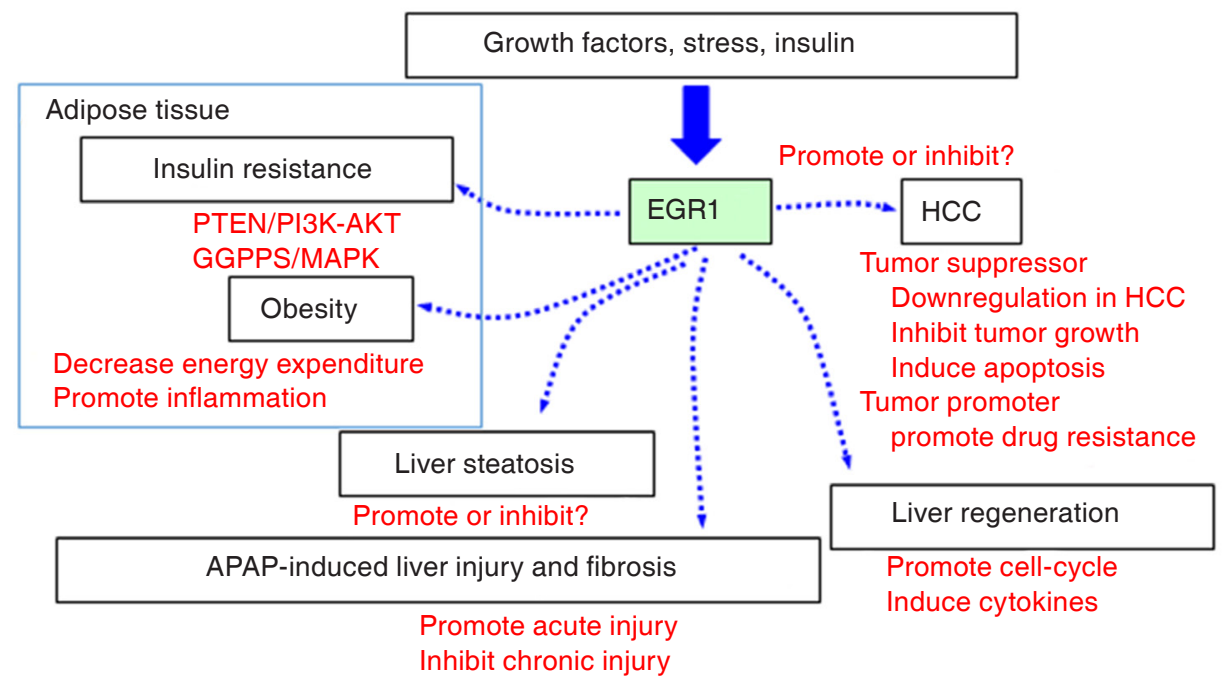

Figure 2: Model of EGR1 function in metabolic diseases and liver diseases. EGR1 is induced in response to various stimuli such as growth factors, stress, and insulin signal. EGR1 regulates a wide array of transcriptional targets involved in multiple biological functions related to lipid and glucose metabolism. In particular, increase of EGR1 in adipose tissue is associated with insulin resistance and obesity. In the liver, dysregulation of EGR1 is associated with liver steatosis. EGR1 promotes acute acetaminophen (APAP)-induced liver injury while attenuates chronic APAP-induced liver fibrosis. EGR1 is important for liver regeneration as it promotes cell-cycle entry and progression, as well as stimulates production of cytokines required for tissue repair. Finally, dysregulation of EGR1 associates with HCC development. EGR1 regulates HCC tumor growth and apoptosis, and is involved in hypoxia-induced drug resistance. EGR1: early growth response 1; HCC: hepatocellular carcinoma

derivative, HS-1200 ${ }^{[89]}$. Collectively, these studies have demonstrated that Egr1 functions as a tumor suppressor in HCC via inhibiting tumor proliferation and promoting apoptosis.

In addition, Egr1 regulates the expression of a large number of genes required for suppressing HCC growth, including $\mathrm{PTEN}{ }^{[38]}$, a very well known tumor suppressor that inhibits PI3K signaling pathway in HCC. EGR1 protein sumoylation is required for activation of PTEN transcription, in which the phosphorylation of EGR1 by AKT at S350 and T309 allows EGR1 protein sumoylation $^{[90]}$. In addition, Egr1/PTEN axis is essential for ribonucleotide reductase regulatory TP53 inducible subunit M2B (RRM2B) inhibition on HCC cell migration ${ }^{[91]}$. Recently, Wang et al. ${ }^{[92]}$ has described a cascade, involving Egr1, microRNA-203a (miR-203a), and homeobox D3 (HOXD3), inhibits $\mathrm{HCC}$ tumorigenesis. Through both in vitro and in vivo studies, the authors have demonstrated that Egr1 directly activates miR-203a expression by binding to the miR-203a promoter that results in suppression on HOXD3 ${ }^{[92]}$. Taken together, these studies support an anti-tumor role of Egr1 in HCC.

Contrasting the anti-tumorigenic role of Egr1 is study indicating that Egr1 is associated with $\mathrm{HCC}$ tumorigenesis. In a study using cDNA microarray and chromatin immunoprecipitation (ChIP) assay to assess the genes associated with tumor angiogenesis, Egr1 is identified as a key player to mediate HGF-induced upregulation of vascular endothelial growth factor and IL-8 ${ }^{[93]}$. In an attempt to identify early biomarkers of HCC, Archer et al. ${ }^{[94]}$ has performed gene expression microarray analyses in HCC tissues and revealed that Egr1 and vesicle associated membrane protein-2 are positively correlated to hepatitis virus-induced HCC. Additionally, G protein-coupled receptor kinase2 overexpression reduces insulin-like growth factor 1-induced HCC cell proliferation and migration that is mediated by decreasing Egr $1^{[95]}$. All these studies suggest that activation of Egr1 might promote $\mathrm{HCC}$ development.

Additionally, Egr1 is described to contribute to hypoxiainduced HCC cells' resistance against anticancer drugs $^{[74,96]}$. One of the proposed mechanisms behind such phenomenon connects Egr1, hypoxia, and microtubules. Egr1 is co-localized with microtubules and mediates hypoxia-induced stabilization of microtubules from disassembly ${ }^{[96]}$. Expected, knockdown of Egr1 improves drug effectiveness under hypoxic conditions ${ }^{[96]}$. Another mechanism connects Egr1, hypoxia, and autophagy to HCC drug resistance. Autophagy contributes to the HCC cells resistance against chemotherapeutic agents under hypoxic conditions $^{[97-99]}$. Egr1 transcriptionally regulates hypoxia-induced autophagy by binding to the promoter of microtubule-associated protein 1 light chain 3 and promotes autophagosomes formation in HCC cells ${ }^{[74]}$. Collectively, these studies suggest that inhibiting Egr1 expression or function to increase tumor cells' 
sensitivity to chemotherapeutics could be applied as a novel approach for HCC therapy. In addition, whether the current discrepancies on Egr1 function in $\mathrm{HCC}$ could be due to a dual role of Egr1 during HCC development, first acting as an activator and then as a repressor, still remains elusive and requires further investigation.

\section{CONCLUSION}

As a Zinc-finger transcription factor, Egr1 has a diverse range of functions implicated in various cell types. The major roles of Egr1 in liver diseases are summarized and depicted in Figure 2. Research efforts using various animal models such as fatty liver, liver injury and fibrosis have contributed greatly to the elucidation of Egr1 liver-specific function. However, in some instances, such as in insulin signaling as well as $\mathrm{HCC}$ studies, the data regarding the role of Egr1 are contradictory. Hence, much progress is required to uncover and characterize the role of Egr1 in various types of cells in the regulation of normal liver function. For example, studying the effects of insulin signaling, APAP, ethanol, or $\mathrm{CCL}_{4}$ in hepatocyte-specific or macrophage-specific Egr1 knockout models are greatly appreciated. Utilization of primary cell cultures (such as hepatocytes, stellate cells, and macrophages) from normal liver to assess Egr1 functions may also aid in elucidation of liver-specific Egr1 regulation. On the other hand, due to its regulation of key fibrotic mediators, Egr1 may be a promising target for antifibrotic therapy. Overall, much progress is required to uncover and characterize the cell-type specific role of Egr1 in the liver. Improving our understanding of Egr1 in liver metabolism and liver cancer may provide new insights to facilitate developing novel treatments or prevention strategies for liver diseases.

\section{DECLARATIONS}

\section{Authors' contributions}

Reviewed the literature and wrote the manuscript: $\mathrm{N}$. Magee, Y. Zhang

\section{Financial support and sponsorship}

This work was supported by the National Institutes of Health grants NCIK22CA184146, P20GM103549, P20GM103418, P30GM118247, and T32ES007079.

\section{Conflicts of Interest}

The authors declare no conflicts of interest.

\section{Patient consent Not applicable.}

Ethics approval

Not applicable.

\section{REFERENCES}

1. Milbrandt J. A nerve growth factor-induced gene encodes a possible transcriptional regulatory factor. Science 1987;238:797-9.

2. Kaufmann K, Bach K, Thiel G. The extracellular signal-regulated protein kinases Erk1/Erk2 stimulate expression and biological activity of the transcriptional regulator Egr-1. Biol Chem 2001;382:1077-81.

3. Gashler AL, Swaminathan S, Sukhatme VP. A novel repression module, an extensive activation domain, and a bipartite nuclear localization signal defined in the immediate-early transcription factor Egr-1. Mol Cell Biol 1993;13:4556-71.

4. Cui L, Schoene NW, Zhu L, Fanzo JC, Alshatwi A, Lei KY. Zinc depletion reduced Egr-1 and HNF-3beta expression and apolipoprotein A-I promoter activity in Hep G2 cells. Am J Physiol Cell Physiol 2002;283:C623-30.

5. Duclot F, Kabbaj M. The role of early growth response 1 (EGR1) in brain plasticity and neuropsychiatric disorders. Front Behav Neurosci 2017;11:35.

6. Swirnoff AH, Apel ED, Svaren J, Sevetson BR, Zimonjic DB Popescu NC, Milbrandt J. Nab1, a corepressor of NGFI-A (Egr-1), contains an active transcriptional repression domain. Mol Cell Biol 1998; 18:512-24.

7. Sevetson BR, Svaren J, Milbrandt J. A novel activation function for NAB proteins in EGR-dependent transcription of the luteinizing hormone beta gene. J Biol Chem 2000;275:9749-57.

8. Li XJ, Wang KM, Xu Y, Wang ZH, Xia AD, Chen SS, Qian GX Ionizing radiation-regulated killing of human hepatoma cells by liposome-mediated CDglyTK gene delivery. Sheng Wu Ниа Хие Yu Sheng Wu Wu Li Xue Bao (Shanghai) 2003;35:64-70. (in Chinese)

9. Keeton $\mathrm{AB}$, Bortoff KD, Bennett WL, Franklin JL, Venable DY, Messina JL. Insulin-regulated expression of Egr-1 and Krox20: dependence on ERK1/2 and interaction with p38 and PI3-kinase pathways. Endocrinology 2003;144:5402-10.

10. Chen SJ, Ning H, Ishida W, Sodin-Semrl S, Takagawa S, Mori Y, Varga J. The early-immediate gene EGR-1 is induced by transforming growth factor-beta and mediates stimulation of collagen gene expression. J Biol Chem 2006;281:21183-97.

11. Zhang Y, Bonzo JA, Gonzalez FJ, Wang L. Diurnal regulation of the early growth response 1 (Egr-1) protein expression by hepatocyte nuclear factor 4alpha (HNF4alpha) and small heterodimer partner (SHP) cross-talk in liver fibrosis. J Biol Chem 2011;286:29635-43.

12. Zhang Y, Xu N, Xu J, Kong B, Copple B, Guo GL, Wang L. E2F1 is a novel fibrogenic gene that regulates cholestatic liver fibrosis through the Egr-1/SHP/EID1 network. Hepatology 2014;60:919-30.

13. Zhu HY, Bai WD, Wang HT, Xie ST, Tao K, Su LL, Liu JQ, Yang XK, Li J, Wang YC, He T, Han JT, Hu DH. Peroxisome proliferatoractivated receptor-gamma agonist inhibits collagen synthesis in human keloid fibroblasts by suppression of early growth response-1 expression through upregulation of miR-543 expression. Am J Cancer Res 2016;6:1358-70.

14. Dussmann P, Pagel JI, Vogel S, Magnusson T, Zimmermann R, Wagner E, Schaper W, Ogris M, Deindl E. Live in vivo imaging of Egr-1 promoter activity during neonatal development, liver regeneration and wound healing. BMC Dev Biol 2011;11:28.

15. Christy B, Nathans D. DNA binding site of the growth factor-inducible protein Zif268. Proc Natl Acad Sci U S A 1989;86:8737-41.

16. Fagerberg L, Hallstrom BM, Oksvold P, Kampf C, Djureinovic D, Odeberg J, Habuka M, Tahmasebpoor S, Danielsson A, Edlund K, Asplund A, Sjostedt E, Lundberg E, Szigyarto CA, Skogs M, Takanen JO, Berling H, Tegel H, Mulder J, Nilsson P, Schwenk JM, 
Lindskog C, Danielsson F, Mardinoglu A, Sivertsson A, von Feilitzen K, Forsberg M, Zwahlen M, Olsson I, Navani S, Huss M, Nielsen J, Ponten F, Uhlen M. Analysis of the human tissue-specific expression by genome-wide integration of transcriptomics and antibody-based proteomics. Mol Cell Proteomics 2014;13:397-406.

17. Yang H, Lee JH, Noh JK, Kim HC, Park CJ, Park JW, Kim KK. Expression pattern of early growth response gene 1 during olive flounder (paralichthys olivaceus) embryonic development. Dev Reprod 2014;18:233-40.

18. Pritchard MT, Malinak RN, Nagy LE. Early growth response (EGR)1 is required for timely cell-cycle entry and progression in hepatocytes after acute carbon tetrachloride exposure in mice. Am J Physiol Gastrointest Liver Physiol 2011;300:G1124-31.

19. Veyrac A, Gros A, Bruel-Jungerman E, Rochefort C, Kleine Borgmann FB, Jessberger S, Laroche S. Zif268/egr1 gene controls the selection, maturation and functional integration of adult hippocampal newborn neurons by learning. Proc Natl Acad Sci U S A 2013;110:7062-7.

20. Zhang J, Zhang Y, Sun T, Guo F, Huang S, Chandalia M, Abate N, Fan D, Xin HB, Chen YE, Fu M. Dietary obesity-induced Egr-1 in adipocytes facilitates energy storage via suppression of FOXC2. Sci Rep 2013;3:1476.

21. Yang YM, Fang F, Li X, Yu L, Wang ZC. TRAIL overexpression co-regulated by Egr1 and HRE enhances radiosensitivity of hypoxic A549 cells depending on its apoptosis inducing role. Oncol Rep 2017;37:533-9.

22. Bhattacharyya S, Wu M, Fang F, Tourtellotte W, Feghali-Bostwick C, Varga J. Early growth response transcription factors: key mediators of fibrosis and novel targets for anti-fibrotic therapy. Matrix Biol 2011;30:235-42.

23. Kobayashi D, Yamada M, Kamagata C, Kaneko R, Tsuji N, Nakamura M, Yagihashi A, Watanabe N. Overexpression of early growth response-1 as a metastasis-regulatory factor in gastric cancer. Anticancer Res 2002;22:3963-70.

24. Gokey NG, Lopez-Anido C, Gillian-Daniel AL, Svaren J. Early growth response 1 (Egr1) regulates cholesterol biosynthetic gene expression. J Biol Chem 2011;286:29501-10.

25. Mohn KL, Laz TM, Melby AE, Taub R. Immediate-early gene expression differs between regenerating liver, insulin-stimulated H-35 cells, and mitogen-stimulated Balb/c 3T3 cells. Liver-specific induction patterns of gene 33, phosphoenolpyruvate carboxykinase, and the jun, fos, and egr families. J Biol Chem 1990;265:21914-21.

26. Rui L. Energy metabolism in the liver. Compr Physiol 2014;4:177-97.

27. Bechmann LP, Hannivoort RA, Gerken G, Hotamisligil GS, Trauner M, Canbay A. The interaction of hepatic lipid and glucose metabolism in liver diseases. J Hepatol 2012;56:952-64.

28. Josefsen K, Sorensen LR, Buschard K, Birkenbach M. Glucose induces early growth response gene (Egr-1) expression in pancreatic beta cells. Diabetologia 1999;42:195-203.

29. Hasan RN, Phukan S, Harada S. Differential regulation of early growth response gene-1 expression by insulin and glucose in vascular endothelial cells. Arterioscler Thromb Vasc Biol 2003;23:988-93.

30. Harada S, Esch GL, Holgado-Madruga M, Wong AJ. Grb-2-associated binder-1 is involved in insulin-induced egr-1 gene expression through its phosphatidylinositol 3'-kinase binding site. DNA Cell Biol 2001;20:223-9.

31. Gousseva N, Kugathasan K, Chesterman CN, Khachigian LM. Early growth response factor-1 mediates insulin-inducible vascular endothelial cell proliferation and regrowth after injury. $J$ Cell Biochem 2001;81:523-34.

32. Barroso I, Santisteban P. Insulin-induced early growth response gene (Egr-1) mediates a short term repression of rat malic enzyme gene transcription. J Biol Chem 1999;274:17997-8004.

33. Streeper RS, Chapman SC, Ayala JE, Svitek CA, Goldman JK, Cave
A, O'Brien RM. A phorbol ester-insensitive AP-1 motif mediates the stimulatory effect of insulin on rat malic enzyme gene transcription. Mol Endocrinol 1998;12:1778-91

34. Kilbourne EJ, Widom R, Harnish DC, Malik S, Karathanasis SK Involvement of early growth response factor Egr-1 in apolipoprotein AI gene transcription. J Biol Chem 1995;270:7004-10.

35. Shen N, Yu X, Pan FY, Gao X, Xue B, Li CJ. An early response transcription factor, Egr-1, enhances insulin resistance in type 2 diabetes with chronic hyperinsulinism. J Biol Chem 2011;286:1450815.

36. Biddinger SB, Kahn CR. From mice to men: insights into the insulin resistance syndromes. Annu Rev Physiol 2006;68:123-58.

37. Fujishiro M, Gotoh Y, Katagiri H, Sakoda H, Ogihara T, Anai M, Onishi Y, Ono H, Abe M, Shojima N, Fukushima Y, Kikuchi M, Oka Y, Asano T. Three mitogen-activated protein kinases inhibit insulin signaling by different mechanisms in 3T3-L1 adipocytes. Mol Endocrinol 2003;17:487-97.

38. Virolle T, Adamson ED, Baron V, Birle D, Mercola D, Mustelin T, de Belle I. The Egr-1 transcription factor directly activates PTEN during irradiation-induced signalling. Nat Cell Biol 2001;3:1124-8.

39. Shen N, Gong T, Wang JD, Meng FL, Qiao L, Yang RL, Xue B, Pan FY, Zhou XJ, Chen HQ, Ning W, Li CJ. Cigarette smoke-induced pulmonary inflammatory responses are mediated by EGR-1/GGPPS/ MAPK signaling. Am J Pathol 2011;178:110-8.

40. Yu X, Shen N, Zhang ML, Pan FY, Wang C, Jia WP, Liu C, Gao Q, Gao X, Xue B, Li CJ. Egr-1 decreases adipocyte insulin sensitivity by tilting PI3K/Akt and MAPK signal balance in mice. EMBO J 2011;30:3754-65.

41. Weng K, Hu H, Xu AG, Khaitovich P, Somel M. Mechanisms of dietary response in mice and primates: a role for EGR1 in regulating the reaction to human-specific nutritional content. PLoS One 2012;7:e43915.

42. McMullen MR, Pritchard MT, Wang Q, Millward CA, Croniger CM, Nagy LE. Early growth response-1 transcription factor is essential for ethanol-induced fatty liver injury in mice. Gastroenterology 2005;128:2066-76.

43. Song $\mathrm{H}$, Zheng Z, Wu J, Lai J, Chu Q, Zheng X. White pitaya (hylocereus undatus) juice attenuates insulin resistance and hepatic steatosis in diet-induced obese mice. PLoS One 2016;11:e149670.

44. Ference BA, Ginsberg HN, Graham I, Ray KK, Packard CJ, Bruckert E, Hegele RA, Krauss RM, Raal FJ, Schunkert H, Watts GF, Boren J, Fazio S, Horton JD, Masana L, Nicholls SJ, Nordestgaard BG, van de Sluis B, Taskinen MR, Tokgozoglu L, Landmesser U, Laufs U, Wiklund O, Stock JK, Chapman MJ, Catapano AL. Low-density lipoproteins cause atherosclerotic cardiovascular disease. 1. Evidence from genetic, epidemiologic, and clinical studies. A consensus statement from the European Atherosclerosis Society Consensus Panel. Eur Heart J 2017;38:2459-72.

45. Li T, Chiang JY. Regulation of bile acid and cholesterol metabolism by PPARs. PPAR Res 2009;2009:501739.

46. Madison BB. Srebp2: a master regulator of sterol and fatty acid synthesis. J Lipid Res 2016;57:333-5.

47. Sanchez-Infantes D, White UA, Elks CM, Morrison RF, Gimble JM Considine RV, Ferrante AW, Ravussin E, Stephens JM. Oncostatin m is produced in adipose tissue and is regulated in conditions of obesity and type 2 diabetes. J Clin Endocrinol Metab 2014;99:E217-25.

48. Zhou Y, Zhang F, Abidi P, Lin M, Thiel G, Liu J. Blockage of oncostatin $\mathrm{M}$-induced LDL receptor gene transcription by a dominantnegative mutant of C/EBPbeta. Biochem J 2006;397:101-8.

49. Zhang F, Ahlborn TE, Li C, Kraemer FB, Liu J. Identification of Egr1 as the oncostatin M-induced transcription activator that binds to sterol-independent regulatory element of human LDL receptor promoter. J Lipid Res 2002;43:1477-85. 
50. Taub R. Liver regeneration: from myth to mechanism. Nat Rev Mol Cell Biol 2004;5:836-47.

51. Song Z, Gupta K, Ng IC, Xing J, Yang YA, Yu H. Mechanosensing in liver regeneration. Semin Cell Dev Biol 2017; doi: 10.1016/j. semcdb.2017.07.041

52. Tao Y, Wang M, Chen E, Tang H. Liver Regeneration: Analysis of the Main Relevant Signaling Molecules. Mediators Inflamm 2017;2017:4256352.

53. Bohm F, Kohler UA, Speicher T, Werner S. Regulation of liver regeneration by growth factors and cytokines. EMBO Mol Med 2010;2:294-305

54. Dooley S, ten Dijke P. TGF-beta in progression of liver disease. Cell Tissue Res 2012;347:245-56.

55. Sacilotto N, Castillo J, Riffo-Campos AL, Flores JM, Hibbitt O, WadeMartins R, Lopez C, Rodrigo MI, Franco L, Lopez-Rodas G. Growth arrest specific 1 (Gas1) gene overexpression in liver reduces the in vivo progression of murine hepatocellular carcinoma and partially restores gene expression levels. PLoS One 2015;10:e0132477.

56. Biesiada E, Krawczyk Z, Chorazy M. Expression of c-jun and Egr-1 genes in rat liver in response to partial hepatectomy, and injection of turpentine. Cell Biol Int Rep 1992;16:53-62.

57. Peng Y, Du K, Ramirez S, Diamond RH, Taub R. Mitogenic upregulation of the PRL-1 protein-tyrosine phosphatase gene by Egr-1. Egr-1 activation is an early event in liver regeneration. J Biol Chem 1999;274:4513-20.

58. Liao Y, Shikapwashya ON, Shteyer E, Dieckgraefe BK, Hruz PW, Rudnick DA. Delayed hepatocellular mitotic progression and impaired liver regeneration in early growth response-1-deficient mice. J Biol Chem 2004;279:43107-16.

59. McKee SC, Thompson CS, Sabourin LA, Hakim AM. Regulation of expression of early growth response transcription factors in rat primary cortical neurons by extracellular ATP. Brain Res 2006;1088:1-11.

60. Tackett BC, Sun H, Mei Y, Maynard JP, Cheruvu S, Mani A, Hernandez-Garcia A, Vigneswaran N, Karpen SJ, Thevananther S. P2Y2 purinergic receptor activation is essential for efficient hepatocyte proliferation in response to partial hepatectomy. Am J Physiol Gastrointest Liver Physiol 2014;307:G1073-87.

61. Greenbaum LE, Li W, Cressman DE, Peng Y, Ciliberto G, Poli $\mathrm{V}$, Taub R. CCAAT enhancer- binding protein beta is required for normal hepatocyte proliferation in mice after partial hepatectomy. $J$ Clin Invest 1998;102:996-1007.

62. Li W, Liang X, Leu JI, Kovalovich K, Ciliberto G, Taub R. Global changes in interleukin-6-dependent gene expression patterns in mouse livers after partial hepatectomy. Hepatology 2001;33:1377-86.

63. Lai S, Yuan J, Zhao D, Shen N, Chen W, Ding Y, Yu D, Li J, Pan F, Zhu M, Li C, Xue B. Regulation of mice liver regeneration by early growth response-1 through the GGPPS/RAS/MAPK pathway. Int $J$ Biochem Cell Biol 2015;64:147-54.

64. Donohue TM Jr, Osna NA, Trambly CS, Whitaker NP, Thomes PG, Todero SL, Davis JS. Early growth response-1 contributes to steatosis development after acute ethanol administration. Alcohol Clin Exp Res 2012;36:759-67.

65. Subrata LS, Lowes KN, Olynyk JK, Yeoh GC, Quail EA, Abraham LJ. Hepatic expression of the tumor necrosis factor family member lymphotoxin-beta is regulated by interleukin (IL)-6 and IL-1beta: transcriptional control mechanisms in oval cells and hepatoma cell lines. Liver Int 2005;25:633-46.

66. Mueller L, Broering DC, Meyer J, Vashist Y, Goettsche J, Wilms C, Rogiers X. The induction of the immediate-early-genes Egr-1, PAI-1 and PRL-1 during liver regeneration in surgical models is related to increased portal flow. J Hepatol 2002;37:606-12.

67. Pritchard MT, Nagy LE. Hepatic fibrosis is enhanced and accompanied by robust oval cell activation after chronic carbon tetrachloride administration to Egr-1-deficient mice. Am J Pathol 2010;176:274352.

68. Bryant M, Drew GM, Houston P, Hissey P, Campbell CJ, Braddock M. Tissue repair with a therapeutic transcription factor. Hum Gene Ther 2000;11:2143-58.

69. Haas TL, Stitelman D, Davis SJ, Apte SS, Madri JA. Egr-1 mediates extracellular matrix-driven transcription of membrane type 1 matrix metalloproteinase in endothelium. J Biol Chem 1999;274:22679-85.

70. Pritchard MT, McCracken JM. Identifying novel targets for treatment of liver fibrosis: what can we learn from injured tissues which heal without a scar? Curr Drug Targets 2015;16:1332-46.

71. Alexander D, Judex M, Meyringer R, Weis-Klemm M, Gay S, MullerLadner U, Aicher WK. Transcription factor Egr-1 activates collagen expression in immortalized fibroblasts or fibrosarcoma cells. Biol Chem 2002;383:1845-53.

72. Chen WN, Oon CJ, Leong AL, Koh S, Teng SW. Expression of integrated hepatitis $\mathrm{B}$ virus $\mathrm{X}$ variants in human hepatocellular carcinomas and its significance. Biochem Biophys Res Commun 2000;276:885-92.

73. Xie Y, McGill MR, Dorko K, Kumer SC, Schmitt TM, Forster J, Jaeschke H. Mechanisms of acetaminophen-induced cell death in primary human hepatocytes. Toxicol Appl Pharmacol 2014;279:26674.

74. Peng WX, Xiong EM, Ge L, Wan YY, Zhang CL, Du FY, Xu M, Bhat RA, Jin J, Gong AH. Egr-1 promotes hypoxia-induced autophagy to enhance chemo-resistance of hepatocellular carcinoma cells. Exp Cell Res 2016;340:62-70.

75. Watelet J, Laurent V, Bressenot A, Bronowicki JP, Larrey D, PeyrinBiroulet L. Toxicity of chronic paracetamol ingestion. Aliment Pharmacol Ther 2007;26:1543-4; author reply 1545-6.

76. Pang C, Shi L, Sheng Y, Zheng Z, Wei H, Wang Z, Ji L. Caffeic acid attenuated acetaminophen-induced hepatotoxicity by inhibiting ERK1/2-mediated early growth response-1 transcriptional activation. Chem Biol Interact 2016;260:186-95.

77. Bai Q, Yan H, Sheng Y, Jin Y, Shi L, Ji L, Wang Z. Long-term acetaminophen treatment induced liver fibrosis in mice and the involvement of Egr-1. Toxicology 2017;382:47-58.

78. Gitenay D, Baron VT. Is EGR1 a potential target for prostate cancer therapy? Future Oncol 2009;5:993-1003.

79. Yuan S, Wen J, Cheng J, Shen W, Zhou S, Yan W, Shen L, Luo A, Wang S. Age-associated up-regulation of EGR1 promotes granulosa cell apoptosis during follicle atresia in mice through the NF-kappaB pathway. Cell Cycle 2016;15:2895-905.

80. Shareef MM, Cui N, Burikhanov R, Gupta S, Satishkumar S, Shajahan S, Mohiuddin M, Rangnekar VM, Ahmed MM. Role of tumor necrosis factor-alpha and TRAIL in high-dose radiation-induced bystander signaling in lung adenocarcinoma. Cancer Res 2007;67:11811-20.

81. Wang F, Kuang Y, Salem N, Anderson PW, Lee Z. Cross-species hybridization of woodchuck hepatitis viral infection-induced woodchuck hepatocellular carcinoma using human, rat and mouse oligonucleotide microarrays. J Gastroenterol Hepatol 2009;24:60517.

82. Choi EJ, Yoo NJ, Kim MS, An CH, Lee SH. Putative tumor suppressor genes EGR1 and BRSK1 are mutated in gastric and colorectal cancers. Oncology 2016;91:289-94.

83. Lu Z, Ghosh S, Wang Z, Hunter T. Downregulation of caveolin-1 function by EGF leads to the loss of E-cadherin, increased transcriptional activity of beta-catenin, and enhanced tumor cell invasion. Cancer Cell 2003;4:499-515.

84. Engelman JA, Zhang XL, Razani B, Pestell RG, Lisanti MP. p42/44 MAP kinase-dependent and -independent signaling pathways regulate caveolin-1 gene expression. Activation of Ras-MAP kinase and protein kinase a signaling cascades transcriptionally down-regulates 
caveolin-1 promoter activity. J Biol Chem 1999;274:32333-41.

85. Dhillon AS, Hagan S, Rath O, Kolch W. MAP kinase signalling pathways in cancer. Oncogene 2007;26:3279-90.

86. Berger E, Vega N, Vidal H, Geloen A. Gene network analysis leads to functional validation of pathways linked to cancer cell growth and survival. Biotechnol J 2012;7:1395-404

87. Yang W, Zhao JG, Li XY, Gong SL, Cao JP. Anti-tumor effect of 125I-UdR in combination with Egr-1 promoter-based IFNgamma gene therapy in vivo. Radiat Environ Biophys 2010;49:705-14.

88. Hao MW, Liang YR, Liu YF, Liu L, Wu MY, Yang HX. Transcription factor EGR-1 inhibits growth of hepatocellular carcinoma and esophageal carcinoma cell lines. World J Gastroenterol 2002;8:203-7.

89. Park SE, Lee SW, Hossain MA, Kim MY, Kim MN, Ahn EY, Park YC, Suh H, Kim GY, Choi YH, Kim ND. A chenodeoxycholic derivative, HS-1200, induces apoptosis and cell cycle modulation via Egr-1 gene expression control on human hepatoma cells. Cancer Lett 2008;270:77-86

90. Yu J, Zhang SS, Saito K, Williams S, Arimura Y, Ma Y, Ke Y, Baron V, Mercola D, Feng GS, Adamson E, Mustelin T. PTEN regulation by Akt-EGR1-ARF-PTEN axis. EMBO J 2009;28:21-33.

91. Tian H, Ge C, Li H, Zhao F, Hou H, Chen T, Jiang G, Xie H, Cui Y, Yao M, Li J. Ribonucleotide reductase M2B inhibits cell migration and spreading by early growth response protein 1-mediated phosphatase and tensin homolog/Akt1 pathway in hepatocellular carcinoma. Hepatology 2014;59:1459-70.

92. Wang L, Sun H, Wang X, Hou N, Zhao L, Tong D, He K, Yang Y, Song T, Yang J, Huang C. EGR1 mediates miR-203a suppress the hepatocellular carcinoma cells progression by targeting HOXD3 through EGFR signaling pathway. Oncotarget 2016;7:45302-16.

93. Lee KH, Kim JR. Hepatocyte growth factor induced up-regulations of VEGF through Egr-1 in hepatocellular carcinoma cells. Clin Exp Metastasis 2009;26:685-92.

94. Archer KJ, Mas VR, David K, Maluf DG, Bornstein K, Fisher RA. Identifying genes for establishing a multigenic test for hepatocellular carcinoma surveillance in hepatitis $\mathrm{C}$ virus-positive cirrhotic patients. Cancer Epidemiol Biomarkers Prev 2009;18:2929-32.

95. Ma Y, Han CC, Huang Q, Sun WY, Wei W. GRK2 overexpression inhibits IGF1-induced proliferation and migration of human hepatocellular carcinoma cells by downregulating EGR1. Oncol Rep 2016;35:3068-74

96. Peng WX, Pan FY, Liu XJ, Ning S, Xu N, Meng FL, Wang YQ, Li CJ. Hypoxia stabilizes microtubule networks and decreases tumor cell chemosensitivity to anticancer drugs through Egr-1. Anat Rec (Hoboken) 2010;293:414-20.

97. Chang Y, Yan W, He X, Zhang L, Li C, Huang H, Nace G, Geller DA, Lin J, Tsung A. miR-375 inhibits autophagy and reduces viability of hepatocellular carcinoma cells under hypoxic conditions. Gastroenterology 2012;143:177-87.e8.

98. Toshima $\mathrm{T}$, Shirabe $\mathrm{K}$, Matsumoto $\mathrm{Y}$, Yoshiya S, Ikegami $\mathrm{T}$, Yoshizumi T, Soejima Y, Ikeda T, Maehara Y. Autophagy enhances hepatocellular carcinoma progression by activation of mitochondrial beta-oxidation. J Gastroenterol 2014;49:907-16.

99. Guo XL, Li D, Sun K, Wang J, Liu Y, Song JR, Zhao QD, Zhang SS, Deng WJ, Zhao X, Wu MC, Wei LX. Inhibition of autophagy enhances anticancer effects of bevacizumab in hepatocarcinoma. $J$ Mol Med (Berl) 2013;91:473-83. 